\author{
JURNAL PENJAMINAN MUTU \\ LEMBAGA PENJAMINAN MUTU \\ UNIVERSITAS HINDU NEGERI \\ I GUSTI BAGUS SUGRIWA DENPASAR
}

Volume 7 Nomor 22021

ISSN : 2407-912X (Cetak)

ISSN : 2548-3110 (Online)

http://ejournal.ihdn.ac.id/index.php/JPM

\title{
PENGEMBANGAN MODEL PENDIDIKAN AGAMA HINDU BERBASIS GLOKALISASI UNTUK PENINGKATAN MUTU SISWA SD KABUPATEN BULELENG
}

\author{
Oleh \\ Ni Nyoman Lisna Handayani ${ }^{1}$, I Putu Suardipa ${ }^{2}$, Ni Ketut Erna Muliastrini ${ }^{3}$ \\ ${ }^{1) 2}$ STAHN Mpu Kuturan Singaraja, ${ }^{3}$ STKIP Agama Hindu Amlapura \\ $\underline{\text { lisnahandayani201@gmail.com }}^{1}$, putu.suardipa@yahoo.com ${ }^{2}$, ernaketut323@yahoo.com ${ }^{3}$
}

diterima 27 Maret 2021, direvisi 19 Mei 2021, diterbitkan 31 Agustus 2021

\begin{abstract}
In general, the purpose of this study is to produce a glocalization-based Hindu religious education model to improve the quality of elementary school students in Buleleng Regency. This study uses a development research approach type "Prototypical Studies. The data in this study will be collected using: (1) observation guidelines, (2) interview guidelines, (3) questionnaires, (4) document study guidelines, (5) focus groups discussion, and (6) interrater validity. The results showed: First, global character values that are visible and relevant to be integrated in character education based on the spectrum of Vygotsky's social reconstruction theory in Hindu religious education learning for fifth grade elementary school students, namely: honesty, responsibility, discipline, hard work, creative, independent, democracy, objectivity, multicultural, open thinking, social care, opened culture, sex education, anti racism, anti harassment, gender equality, leadership, self respect, national and state honor, environmental care, human rights, morality dignity, and respect for minorities. Second, the reconstruction of the content structure of the Class $V$ Hindu religious education curriculum, namely: mantram dainika upasana, ahimsa, satya and tat tvam asi, moksha as the final goal, harmony in life through the tri hita karana, teacher chess, seeing and getting to know the holy places in Hinduism, the vedic scriptures.
\end{abstract}

\section{Keywords: Hindu Religious Education, Glocalization.}

\section{PENDAHULUAN}

Manusia pada hakikatnya merupakan makhluk individu dan sosial. Sebagai makhluk individu, manusia memiliki karakteristik tersendiri yang membedakan manusia satu dengan manusia lainnya. Terkait dengan manusia sebagai makhluk sosial, mereka tidak terlepas dari interaksi dengan lingkungan hidupnya, yaitu lingkungan fisik dan sosial, sehingga manusia tidak dapat 
hidup sendiri yang diistilahkan dengan makhluk sosial. Manusia dalam menjalani dan memenuhi kebutuhan hidupnya tidak terlepas dari interaksi terhadap lingkungan fisik dan sosialnya. Keadaan ini membawa manusia hidup dalam sebuah kelompok manusia yang disebut masyarakat. Terkait dengan rasa ingin tahu dan proses pemenuhan kebutuhan masyarakat, maka keadaan sosial masyarakat selalu mengalami perubahan mengikuti dinamika kehidupan manusia.

Bersandar pada analisis konseptual dan empiris, serta didukung oleh beberapa teori sebagaimana yang telah disajikan di atas, maka penelitian ini akan diarahkan pada upaya melakukan analisis, pemetaan, pengembangan, pengintegrasian, dan justifikasi terhadap nilai- nilai global yang visibel untuk dijadikan sebagai nilai lokal atau local genius dalam rangka pengembangan materi dan model pendidikan karakter dalam pembelajaran materi Agama hindu di sekolah dasar. Hal ini tampaknya merupakan sesuatu yang "sangat baru", sehingga memiliki urgensi akademis dan praktis yang sangat tinggi dalam kaitannya dengan pengembangan pendidikan karakter dalam konstruksi kurikulum pendidikan formal di Indonesia. Pemilihan mata pelajaran Agama hindu sebagai medium pengintegrasian dan pemodelam glokalisasi didasari oleh rasional bahwa, mata pelajaran inilah yang "terdekat" bilamana kita membicarakan tentang pendidikan karakter, sepanjang nilai dasar karakter yang dimaksudkan adalah Pancasila dalam kapasitasnya sebagai way of life bangsa Indonesia.

Model pembelajaran inovatif merupakan salah satu model pembelajaran yang patut dipertimbangkan untuk meningkatkan kualitas pembelajaran. Model pembelajaran inovatif ini berciri antisipasi dan partisipasi, menyeimbangkan antara kegiatan penyadaran dengan kegiatan pemberdayaan, antara pembentukan otonomi dengan pembentukan integrasi setiap anak. Beberapa model pembelajaran inovatif telah dikembangkan untuk memacu siswa berperan aktif dalam setiap pembelajaran. Siswa diharapkan mampu dan mau meberikan pendapatnya.
Model pembelajaran inovatif menuntut siswa untuk terlibat saling tukar pikiran, berkolaborasi dan berkomunikasi untuk mencapai tujuan pembelajaran yang diinginkan sehingga diharapkan siswa mampu mngembangkan kemampuan komunikasi mereka. Model pembelajaran inovatif juga menekankan pada terjadinya interaksi sosial antara siswa dengan lingkungannya. Vygotsky (dalam Dahar, 2006) menyarankan bahwa dalam pembelajaran interaksi sosial itu penting saat siswa menginternalisasi pemahamanpemahaman yang sulit, masalah-masalah, dan proses yang dihadapinya.

Model rekonstruksi sosial berorientasi pada terciptanya sikap kritis. Siswa diharapkan tidak hanya sekedar menerima apa yang diusung oleh guru, dan guru pun harus siap dengan serangkaian strategi untuk mengajak anak berpikir kritis. Pada dasarnya model rekonstruksi sosial merupakan sebuah pembelajaran yang berpusat pada siswa dan memiliki tujuan untuk memahami dan menghadapi isu-isu atau masalah-masalah sosial yang terjadi di masyarakat, serta menjadikan siswa sebagai aktor dalam perubahan dan perbaikan kondisi sosial menuju yang lebih baik. Guru dalam pembelajaran model ini adalah sebagai pemandu selama proses pembelajaran yang mendorong siswa untuk belajar secara kritis, dalam aspek budaya dan kehidupan sosial siswa.

Pendidikan yang baik, adalah dengan memberikan bantuan kepada anak oleh orang dewasa secara berurutan (scafolding), dan pembantuan nilai-nilai kemasyarakatan (nilai sosial) yang telah diakrabinya, sehingga mereka akan semakin dewasa sejalan dengan kedewasaan nilai yang dipahaminya. Di satu sisi, pembelajaran tidak boleh "memaksa" anak untuk paham dan mengerti, tetapi "harus" memberikan ruang dan waktu kepada mereka untuk membangun sendiri pemahamannya dengan dukungan nilai-nilai diri dan nilai sosial yang ada di sekitarnya. Berdasarkan latar belakang penelitian di atas, dapat dirumuskan masalah penelitian yaitu: 1) Nilai-nilai karakter global apa saja yang 
relevan diglokalisasi berdasarkan spektrum teori rekonstruksi sosial Vygotsky dalam pembelajaran Agama Hindu bagi Siswa SD kelas V di Kabupaten Buleleng? 2) Pola pengorganisasian dan struktur materi pendidikan karakter seperti apa yang relevan dikembangkan dalam pembelajaran Agama Hindu Siswa SD kelas V di Kabupaten Buleleng berdasarkan perspektif glokalisasi dan spektrum teori rekonstruksi sosial Vygotsky?

\section{PEMBAHASAN}

2.1 Nilai-Nilai Karakter yang Relevan Diglokalisasi Berdasarkan Spektrum Teori Rekonstruksi Sosial Vygotsky dalam Pembelajaran Agama Hindu Bagi Siswa SD kelas V di Kabupaten Buleleng

Pendidikan karakter adalah suatu sistem penanaman nilai-nilai karakter kepada warga sekolah yang meliputi komponen pengetahuan, kesadaran atau kemauan, dan tindakan untuk melaksanakan nilai-nilai tersebut. Pendidikan karakter dapat dimaknai sebagai "the deliberate use of all dimensions of school life to foster optimal character development". Dalam pendidikan karakter di sekolah, semua komponen (pemangku pendidikan) harus dilibatkan, termasuk komponen-komponen pendidikan itu sendiri, yaitu isi kurikulum, proses pembelajaran dan penilaian, penanganan atau pengelolaan mata pelajaran, pengelolaan sekolah, pelaksanaan aktivitas atau kegiatan ko-kurikuler, pemberdayaan sarana prasarana, pembiayaan, dan ethos kerja seluruh warga sekolah/lingkungan. Disamping itu, pendidikan karakter dimaknai sebagai suatu perilaku warga sekolah yang dalam menyelenggarakan pendidikan harus berkarakter.

Menurut Ramli (2003), pendidikan karakter memiliki esensi dan makna yang sama dengan pendidikan moral dan pendidikan akhlak. Tujuannya adalah membentuk pribadi anak, supaya menjadi manusia yang baik, warga masyarakat, dan warga negara yang baik. Adapun kriteria manusia yang baik, warga masyarakat yang baik, dan warga negara yang baik bagi suatu masyarakat atau bangsa, secara umum adalah nilai-nilai sosial tertentu, yang banyak dipengaruhi oleh budaya masyarakat dan bangsanya. Oleh karena itu, hakikat pendidikan karakter dalam konteks pendidikan di Indonesia adalah pedidikan nilai, yakni pendidikan nilai-nilai luhur yang bersumber dari budaya bangsa Indonesia sendiri, dalam rangka membina kepribadian generasi muda. Pendidikan karakter berpijak dari karakter dasar manusia, yang bersumber dari nilai moral universal (bersifat absolut) yang bersumber dari agama yang juga disebut sebagai the golden rule. Pendidikan karakter dapat memiliki tujuan yang pasti, apabila berpijak dari nilai-nilai karakter dasar tersebut.

Menurut para ahli psikologi, beberapa nilai karakter dasar tersebut adalah: cinta kepada Tuhan dan ciptaann-Nya (alam dengan isinya), tanggung jawab, jujur, hormat dan santun, kasih sayang, peduli, dan kerjasama, percaya diri, kreatif, kerja keras, dan pantang menyerah, keadilan dan kepemimpinan; baik dan rendah hati, toleransi, cinta damai, dan cinta persatuan. Pendapat lain mengatakan bahwa karakter dasar manusia antara lain, dapat dipercaya, rasa hormat dan perhatian, peduli, jujur, tanggung jawab; kewarganegaraan, ketulusan, berani, tekun, disiplin, visioner, adil, dan punya integritas. Penyelenggaraan pendidikan karakter di sekolah harus berpijak kepada nilai-nilai karakter dasar, yang selanjutnya dikembangkan menjadi nilai-nilai yang lebih banyak atau lebih tinggi (yang bersifat tidak absolut atau bersifat relatif) sesuai dengan kebutuhan, kondisi, dan lingkungan sekolah itu sendiri. Melalui pendidikan karakter diharapkan peserta didik mampu secara mandiri meningkatkan dan menggunakan pengetahuannya, mengkaji dan menginternalisasi serta mempersonalisasi nilai-nilai karakter dan akhlak mulia sehingga terwujud dalam perilakunya sehari-hari.

Nilai karakter global yang visibel dan relevan untuk diintegrasikan dalam pendidikan karakter berdasarkan spektrum teori rekonstruksi sosial Vygotsky dalam 
pembelajaran pendidikan agama hindu bagi siswa sekolah dasar, yaitu: kejujuran, tanggung jawab, disiplin, kerja keras, kreatif, mandiri, demokrasi, objektivitas, multikultur, berpikir terbuka, kepedulian sosial, opened culture, pendidikan seks, anti rasisme, anti pelecehan, kesetaraan gender, kepemimpinan, kehormatan diri, kehormatan bangsa dan negara, peduli lingkungan, hak azazi manusia, morality dignity, dan penghargaan pada minoritas

Bersandar pada hasil cermatan observasi kelas, wawancara, dan kajian dokumendokumen buku paket siswa dan pegangan guru, program semester, persiapan mengajar, dan butir-butir soal pendidikan agama hindu; materi pendidikan agama hindu tersusun atau terstruktur dari materi-materi yang bersifat "informatif", yakni materi-materi yang memberikan informasi kepada siswa tentang pengetahuan, pemahaman atau pengertian mengenai aspek-aspek dari kehidupan manusia dan masyarakat atas dasar "struktur pengetahuan" (structure of knowledge). Secara substantif materi-materi informatif (informative contents) tersebut tersusun dari dua jenis materi utama, yakni: (1) "materi formal" (formal content), dan (2) materi nonformal (non-formal content). Dari kedua substansi tersebut, materi formal masih tetap dominan daripada materi non-formal. Semua materi tersebut sebagai materi-materi substantif yang menstrukturkan atau membangun suatu pengetahuan (structure of knowledge), dimaksudkan untuk memberikan pengetahuan, pemahaman atau pengertian kepada siswa tentang unsure-unsur struktural yang membangun suatu ilmu pengetahuan. Sedangkan unsur-unsur struktural pengetahuan lainnya seperti: sikap; nilai-nilai dan norma; serta keterampilan-keterampilan dasar keilmuan yang merupakan materimateri "prosedural" (pengetahuan tentang "bagaimana melakukan") yang bersifat general dan sesungguhnya tak terpisahkan dari sebuah struktur pengetahuan. Selain itu, jenis dan jenjang kemampuan atau keterampilan keilmuan yang seharusnya dibelajarkan dan bisa dikuasai oleh siswa tersebut, juga masih terlalu umum, tidak spesifik menunjuk pada suatu jenis dan jenjang "kemampuan atau keterampilan dasar" (basic skill and competency) keilmuan tertentu.

\subsection{Struktur Materi Pendidikan Karakter Berbasis Glokalisasi dan Spektrum Teori Rekonstruksi Sosial Vygotsky dalam Pembelajaran Agama Hindu yang Relevan Bagi Siswa SD kelas V di Kabupaten Buleleng}

Piaget menemukan teori epistemologis tentang asal usul pembentukan dan perkembangan pengetahuan pada manusia (epistemology genetik), dan teori tentang struktur internal anak, belum ada satupun ikhtiar keilmuan yang mengarah pada perumusan teori tentang struktur materi kajian (structure of subject matter). Sungguhpun debat teoretis dan filosofis tentang hakikat materi-kajian dalam kurikulum pendidikan sudah terjadi sejak lama. Berdasarkan hasil kajian Piaget tadi, pakar pertama yang mengajukan teori tentang struktur isi materi kajian adalah Jerome S. Bruner (1978) dalam karyanya "Process of Education". Ditegaskan oleh Bruner, bahwa "the structure of a subject" haruslah dikaitkan dengan teori tentang struktur pengetahuan (structure of knowledge). Asumsinya adalah bahwa intelektualitas atau cara-cara manusia membangun pengetahuan "sama atau paralel" bagi semua manusia, tak pandang usia tak terkecuali pada anak dan ilmuwan. Karena itu, "the foundations of any subject may be taught anybody at any age in some regardless of their age" (Bruner, 1978;12, 14, 40).

Berdasarkan preposisi di atas, maka dapat dirumuskan bahwa "anak adalah seorang ilmuwan" (the young child as scientiest) atau "pembangun teori" (children as theory builder). Implikasinya, adalah bahwa struktur materi kurikuler dapat diturunkan dari struktur disiplin ilmu (a structured-oriented curriculum), dan tugas para ilmuwan lah yang memilih dan merumuskan masing-masing struktur disiplin untuk dijadikan sebagai struktur isi kurikulum. Atau seperti dikatakan Shavelson, "a structure of a subject matter, 
ultimately, rests in the minds of the great scientists" (Philips, 1987:139); sejalan dengan "garis berpikir keilmuan" atau "seperti telah ditetapkan oleh para ilmuwan sosial" selama ini.

Pengembangan struktur isi kurikulum berdasarkan "struktur" disiplin ilmu, pada konteks pendidikan ilmu social, memberikan empat keuntungan: (1) isi kurikulum menjadi semakin komprehensif (more comprehensible) karena hanya gagasan dan prinsip dasar tentang obyek yang dikaji; (2) menyederhanakan cara menyimpan dan menggunakan ingatan ketika suatu saat dibutuhkan; (3) memudahkan terjadinya "pengalihan latihan" (transfer of training) kemampuan hal-hal lain, baik dalam situasi khusus (specific transfer of training) maupun dalam segala situasi (non-specific transfer of training); dan (4) dapat mengembangkan ketajaman analisis sehingga dapat membedakan perbedaan antara pengetahuan dasar (elementary knowledge) dengan pengetahuan yang lebih maju (advanced knowledge).

Berdasarkan hasil-hasil implementasi pemikiran tersebut di atas, khususnya dalam pengembangan struktur materi kurikulum pendidikan Agama Hindu Sekolah Dasar, baik dari segi teoretik maupun praktik masih kontroversi, dan memperlihatkan kegagalan. Shaver (Lybarger, 1991) memandang bahwa pemikiran kurikulum Brunerian tersebut akan membawa konsekuensi dan resiko bagi terjadinya "fragmentasi skala tinggi" dilihat dari sisi siswa; bisa mengancam eksistensi pendidikan agama hindu Sekolah Dasar sebagai program pendidikan anak (social studies as education for children). Hasil kajian Savage \& Amstrong (1996:103) juga mengungkapkan bahwa bahan-bahan yang dikembangkan oleh University of Georgia di dalam program "Man: A Course of Study" (MACOS) hingga tahun 1990an masih sedikit mendapat perhatian di dalam pengembangan substansi program pendidikan agama hindu Sekolah Dasar, dan hanya beberapa sekolah saja yang masih menggunakan.

Penerapan kurikulum model Brunerian yang berorientasi esensialistik tersebut juga dapat mendistorsi atau merusak self-concept siswa, terutama dalam rangka pembentukan "jati-diri" atau "karakter" siswa. Hasil hasilkajian mutakhir dari perspektif multikultural yang dilakukan oleh Jegede \& Aikenhead (2000), juga menyimpulkan bahwa keniscayaan kurikuler esensialistik semacam itu, dapat menghambat perkembangan tahapan progresif kognitif anak, mendistorsi atau merusak genuine concepts, indigenous science, atau spontaneous concept siswa tentang alam semesta yang dibangun dan dikembangkan dari keseharian pengalaman personal, sosial dan kulturalnya di masyarakat; mencabut siswa dari situasi nyata yang menjadi basis pembentukan dan penggunaannya; kurang bermakna bagi siswa; dan menunjukkan adanya "hegemoni atau imperialisme pendidikan" atas diri siswa. Bahkan, lebih jauh lagi dapat mendistorsi atau merusak self-concept siswa yang merupakan faktor esensial bagi pembentukan identitas atau karakter siswa.

Pola pengorganisasian muatan di dalam struktur internal anak, baik dalam perspektif konstruktivisme Piaget dan Vygotsky merupakan sebuah "organisasi sistemik" (systemic organization) atau "tubuh informasi dan keyakinan" (a body of information or belief a person) yang tersimpan dalam bentuk "skema-skema" (cognitive and affective schemes) yang saling berkaitan satu dengan lain membangun sebuah "jaringan strukturalfungsional" (a structural and functional systemic relationship with each other). Berpijak pada prinsip struktur internal tadi, maka rekonstruksi struktur isi kurikulum pendidikan agama hindu Sekolah Dasar pun harus merupakan sebuah jaringan organisasi isi yang sistemik, struktural maupun fungsional.

Berdasarkan proposisi itu pula, maka "the structure of a subject" menurut Bruner, Well on his way toward being able to handle a good deal of seemingly new, but in fact, highly related information Grasping the structure of a subject is understanding it in a way that permits many other things to be related to it meaningfully. To learn structure, in short, is to learn how things are related" (Bruner, 
1978:7; Philips,1987:123) Shavelson (Philips, 1987:143) juga berpandangan sama bahwa: "The structure in a student's memory is refered to as cognitive structure: a hypothetical construct referring to the organization (relationships) of concepts in memory". Thus, a subject matter structure in instructional materials to as content structure: the web of concepts (words, symbols) and thier relations in a body on instructional material".

Berdasarkan kutipan di atas, baik Bruner maupun Shavelson belum jelas mengemukakan apa saja unsur-unsur yang membangun sebuah struktur isi kurikulum, kecuali bahwa " the structure of a subject is understanding it in a way that permits many other things to be related to it meaningfully. To learn structure, in short, is to learn how things are related" (Bruner, 1978:7; Philips,1987:123). Struktur isi kurikulum baru diartikan sebagai "relasi atau keterkaitan" di antara bagian-bagian yang membangun struktur materi tersebut. Menurut teori struktur kognitifnya, Piaget mengemukakan bahwa "cognitive schemas" terdiri dari: isi (content), operasi-operasi mental-fisikal (operations), dan fungsi-fungsi intelektual (functions), yang satu dengan lainnya saling berkaitan. Hal yang sama juga terdapat di dalam struktur afektif (affective schemas), "simply the affective aspect of schemes which are otherwise also intellectual schemes"" (Thomas, 1979:295). Di sisi lain, sekalipun Vygotsky juga mengkaji tentang perkembangan kemampuan intelektual anak dari perspektif sosiokultural, akan tetapi dia tidak menyinggung tentang "unsur-unsur dari struktur internal" anak. Kalaupun Vygotsky membahas tentang operasi fungsi-fungsi psikologis ingatan, persepsi, perhatian, dll, tetapi dia lebih fokus pada proses-proses eksternal yaitu pada "alat-alat psikologis" dan kaitannya dengan bekerjanya "fungsi-fungsi psikologis". Tetapi bagaimana sifat dan apa saja operasi-operasi internal yang terjadi, kurang mendapatkan perhatian. Oleh sebab itu, rekonstruksi struktur isi kurikulum lebih didasarkan pada perspektif konstruktivismekognitif Piagetian.
Berdasarkan kajian dan temuan empiris, maka dapat disimpulkan bahwa ada dua kontribusi penting pemikiran Vygotsky yang bisa digunakan sebagai pijakan dalam rekonstruksi struktur isi kurikulum pendidikan agama hindu Sekolah Dasar, yaitu: (1) bahwa hakikat struktur isi kurikulum adalah sosiokultural (their nature are sociocultural character; becoming culturally and socially informed and organized); (2) bahwa struktur isi kurikulum harus menjadi sebagai "alat-alat psikologis" yang mampu memediasi dan menjembatani kemungkinan bekerjanya "fungsi-fungsi psikologis" yang terdapat pada diri siswa.

Vygotsky menegaskan, bahwa "alat-alat psikologis" bersifat determinan terhadap bekerjanya "fungsi-fungsi psikologis". Artinya, fungsi-fungsi psikologis internal ada anak hanya bisa beroperasi dengan baik manakala didukung oleh adanya alat-alat psikologis. Pemikiran Vygotsky tersebut berkaitan erat dengan teorinya tentang batasbatas kemampuan fungsi fungsi internal psikologis anak, yang dikenal sebagai "Zone Perkembangan Berdekatan (ZPB)" (the zone of proximal development $=Z P D)$, yaitu wilayah yang membedakan antara apa yang dapat siswa lakukan sendiri melalui mekanisme-mekanisme atau fungsi-fungsi psikologisnya, karena muatan dan fungsifungsi internal siswa belum sepenuhnya terbentuk (Zone Perkembangan Potensial = ZPP), dengan apa dapat siswa lakukan hanya dengan bantuan orang lain yang lebih dewasa dan kompeten (Zone Perkembangan Aktual = ZPA).

Berpijak pada teori Vygotsky tersebut, maka prinsip yang dapat dijadikan pegangan dalam rekonstruksi struktur isi kurikulum pendidikan agama hindu Sekolah Dasar adalah, bahwa struktur isi kurikulum pendidikan agama hindu Sekolah Dasar harus berwatak sosiokultural, dan berfungsi sebagai alat psikologis yang mampu menjembatani, memfasilitasi, atau memediasi belajar siswa agar berkembang dari ZPP menuju ZPA. Berdasarkan teori Piaget tentang unsur-unsur yang membentuk struktur internal anak di atas, Schwab dan Hirst, kemudian menyusun 
teorinya tentang unsur-unsur struktur pengetahuan. Menurut mereka, selain sebuah struktur pengetahuan sebagai sebuah organisasi dan relasi sistemik, di dalamnya memuat: (1) "struktur substantif" (substantive structure) atau "struktur konseptual" (conceptual structure) atau "ekologi konseptual", dan dalam konsep Piaget disebut "isi"; dan (2) "struktur sintaktik" (syntactical structure) yang dalam konsep Piaget disebut "operasi-operasi". Sementara itu, apa yang Piaget sebut sebagai "affective schemes" tidak terdapat di dalam teori struktur dari Schwab dan Hirst.

Nilai, norma, moral, dan sikap tersebut secara eklektik bersumber dari nilai, norma, dan sikap yang terdapat di dalam agama, budaya, hukum, moral, ilmu pengatahuan, etika, maupun estetika yang: (1) menjadi kesepakatan umum atau bersama, di kalangan masyarakat luas dan komunitas pendidikan agama hindu Sekolah Dasar; dan (2) yang dimiliki dan menjadi acuan personal siswa dalam berpikir, bersikap, dan bertindak dalam latar kehidupan personal dan sosiokulturalnya. Kedua jenis muatan struktur normatif/afektif tersebut secara sinergis harus mampu mendukung, memperkuat, memperluas, dan/atau merekonstruksi struktur normatif/afektif yang terdapat di dalam diri siswa. Berkenaan dengan muatan struktur normatif/afektif yang masih kontroversi yang ada di "wilayah tabu" (closed areas). Rekonstruksi struktur muatan kurikulum pendidikan agama hindu Sekolah Dasar kelas V secara keseluruhan dapat digambarkan sebagai berikut.

Pelajaran 1 Mantram Dainika Upasana:(Pengertian salam Om swastyastu dan salam om santih, santih, santih, om, Membiasakan mengucapkan Dainika upasana, Tata urutan melakukan tri sandhya, Dainika upasana). Pelajaran 2 Ahimsa, Satya dan Tat Tvam Asi (Pengertian Ahimsa, Satya, dan Tat Tvam Asi, Manfaat Penerapan Ahimsa, Satya, dan Tat Tvam Asi, Tujuan penerapan Ahimsa, Satya, dan Tat Tvam Asi). Pelajaran 3 Moksha sebagai Tujuan Akhir (Pengertian Moksha, Jenis- jenis Moksha, Cerita- cerita terkait dengan
Moksha).Pelajaran 4 Keharmonisan Hidup Melalui Tri Hita Karana (Pengertian Tri Hita Karana, Bagian- bagian Tri Hita Karana, Contoh perilaku Tri Hita Karana, Manfaat Tri Hita Karana Bagi Kelangsungan Hidup). Pelajaran 5 Catur Guru (Pengertian Catur Guru, Bagian- bagian Catur Guru, Pentingnya guru dalam sastra). Pelajaran 6 Melihat dan Mengenal Tempat Suci dalam Agama Hindu (Pengertian Tempat Suci, Pengertian Tri Mandala, Bagian- bagian Tri Mandala, Jenisjenis Tempat Suci, Melihat dan Mengenal Tempat Suci, Syarat- syarat Memasuki Tempat Suci, Manfaat dan Fungsi Tempat Suci). Pelajaran 7 Kitab Suci Veda (Pengertian Veda, Kodifikasi Veda, Jenis kitab suci Veda, Veda sebagai Sumber Hukum Hindu).

\section{KESIMPULAN}

Berdasarkan paparan hasil dan pembahasan di atas, maka dapat diformulasikan simpulan penelitian sebagai berikut:

1. Nilai- nilai karakter global yang visibel dan relevan untuk diintegrasikan dalam pendidikan karakter berdasarkan spektrum teori rekonstruksi sosial Vygotsky dalam pembelajaran pendidikan agama hindu bagi siswa sekolah dasar kelas V, yaitu: kejujuran, tanggung jawab, disiplin, kerja keras, kreatif, mandiri, demokrasi, objektivitas, multikultur, berpikir terbuka, kepedulian sosial, opened culture, pendidikan seks, anti rasisme, anti pelecehan, kesetaraan gender, kepemimpinan, kehormatan diri, kehormatan bangsa dan negara, peduli lingkungan, hak azazi manusia, morality dignity, dan penghargaan pada minoritas.

2. Rekonstruksi struktur muatan kurikulum pendidikan agama hindu Sekolah Dasar kelas V secara keseluruhan yaitu: Pelajaran 1 Mantram Dainika Upasana (Pengertian salam Om swastyastu dan salam om santih, santih, santih, om, Membiasakan mengucapkan Dainika upasana, Tata urutan melakukan tri sandhya, Dainika upasana). Pelajaran 2 Ahimsa, Satya dan Tat Tvam Asi 
(Pengertian Ahimsa, Satya, dan Tat Tvam Asi, Manfaat Penerapan Ahimsa, Satya, dan Tat Tvam Asi, Tujuan penerapan Ahimsa, Satya, dan Tat Tvam Asi). Pelajaran 3 Moksha sebagai Tujuan Akhir (Pengertian Moksha, Jenis- jenis Moksha, Cerita- cerita terkait dengan Moksha).Pelajaran 4 Keharmonisan Hidup Melalui Tri Hita Karana (Pengertian Tri Hita Karana, Bagianbagian Tri Hita Karana, Contoh perilaku Tri Hita Karana, Manfaat Tri Hita Karana Bagi Kelangsungan Hidup). Pelajaran 5 Catur Guru (Pengertian Catur Guru, Bagian- bagian Catur Guru, Pentingnya guru dalam sastra). Pelajaran 6 Melihat dan Mengenal Tempat Suci dalam Agama Hindu (Pengertian Tempat Suci, Pengertian Tri Mandala, Bagian- bagian Tri Mandala, Jenis- jenis Tempat Suci, Melihat dan Mengenal Tempat Suci, Syarat- syarat Memasuki Tempat Suci, Manfaat dan Fungsi Tempat Suci). Pelajaran 7 Kitab Suci Veda (Pengertian Veda, Kodifikasi Veda, Jenis kitab suci Veda, Veda sebagai Sumber Hukum Hindu).

\section{DAFTAR PUSTAKA}

Benninga, J. (2019). Moral Character and Civic Education in the Elementary School. Niership: Teachers College Press.

Bruner, J.S. (2017). After John Dewey, What? dalam R.D. Archambault. (2d). Dewey on Education: Appraisals. New York: RandomHouse. 211-227.

Bruner, J.S. (2018). The Process of Education. Cambrigde:

Harvard University Press.

Cerfe. (2017). Glocalization:

Research Study and Policy

Recommendations. Rome:

TheGlocal Forum, CERFE

Group, dan World Bank

Institute.

Clark, Ian. (2017). Globalization and Fragmentation: International Relations in theTwentieth Century.
Oxford \& London: Oxford University Press.

Dantes, N. (2018). Pendidikan

Teknohumanistik (Suatu

Rangkaian Perspektif Dan

Kebijakan Pendidikan Menghadapi

Tantangan Global) (Makalah).

Universitas Pendidikan Ganesha:

Panitia Konaspi

Departemen Pendidikan Nasional Republik

Indonesia. Undang-undang

Republik Indonesia Nomor 20 Tahun

2003 Tentang Sistem Pendidikan

Nasional. Jakarta. 2003. Departemen

Pendidikan Nasional Republik

Indonesia. Peraturan Pemerintah

Republik Indonesia Nomor 19

tahun 2005 Tentang Standar

Nasional Pendidikan. Jakarta 2005.

Departemen Pendidikan Nasional Republik

Indonesia. Undang-undang

Republik Indonesia Nomor 14 Tahun

2005 Tentang Guru dan Dosen.

Jakarta. 2005.

Hidayatullah, M. Furqon. (2020). Pendidikan

Karakter: Membangun Peradaban

Bangsa. Surakarta: Yuma Ristaka.

Kertajaya, Hermawan. (2020). Grow with the Character: The Model Marketing. Jakarta: PT.Gramedia Pustaka Utama.

Koesoema, Doni A. (2017). Pendidikan Karakter: Strategi Mendidik Anak di Zaman Global.Jakarta: Grasindo.

Panggabean, Samsurizal. (2018). "Tantangan-tantangan Globalisasi". Perspektif, Nomor 1, Volume 3.

Plomp. (2018). Development Research in/on Education and Training. Netherlands: Twente University. 